\title{
Hippocampal gene expression dysregulation of Klotho, nuclear factor kappa B and tumor necrosis factor in temporal lobe epilepsy patients
}

Marcelo Ananias Teocchi ${ }^{1}$, Ana Érika Dias Ferreira ${ }^{1}$, Evandro Pinto da Luz de Oliveira ${ }^{2}$, Helder Tedeschi ${ }^{2}$ and Lília D'Souza-Li ${ }^{1 *}$

\begin{abstract}
Background: Previous research in animal seizure models indicates that the pleiotropic cytokine TNF is an important effector/mediator of neuroinflammation and cell death. Recently, it has been demonstrated that TNF downregulates Klotho (KL) through the nuclear factor kappa B (NFkB) system in animal models of chronic kidney disease and colitis. $\mathrm{KL}$ function in the brain is unclear, although Klotho knockout $\left(\mathrm{Kl}^{-/-}\right)$mice exhibit neural degeneration and a reduction of hippocampal synapses. Our aim was to verify if the triad KL-NFKB1-TNF is also dysregulated in temporal lobe epilepsy associated with hippocampal sclerosis (TLE(HS)) patients.

Findings: We evaluated TNF, NFKB1 and KL relative mRNA expression levels by reverse transcription quantitative PCR (RT-qPCR) in resected hippocampal tissue samples from 14 TLE(HS) patients and compared them to five post mortem controls. Four reference genes were used: GAPDH, HPRT1, ENO2 and TBP. We found that TNF expression was dramatically upregulated in TLE(HS) patients $(P<0.005)$. NFKB1 expression was also increased $(P<0.03)$ while $K L$ was significantly downregulated $(P<0.03)$ in $T L E(H S)$ patients. Hippocampal $K L$ expression had an inverse correlation with NFKB1 and TNF.

Conclusions: Our data suggest that, similar to other inflammatory diseases, TNF downregulates KL through NFkB in $T L E(H S)$ patients. The remarkable TNF upregulation in patients is a strong indication of hippocampal chronic inflammation. Our finding of hippocampal $K L$ downregulation has wide implications not only for TLE(HS) but also for other neuronal disorders related to neurodegeneration associated with inflammation.
\end{abstract}

Keywords: Seizures, Hippocampal sclerosis, Neuroinflammation, TNF, KL, NFKB1, GFAP, Reference genes, Calcium homeostasis

\section{Findings}

\section{Introduction}

Temporal lobe epilepsy (TLE) is the most treatment resistant (refractory) partial epilepsy and only $20 \%$ of patients achieve seizure control with antiepileptic drugs (AEDs) [1]. Hippocampal sclerosis (HS) is the main pathological finding observed in excised tissue from TLE patients treated with amygdalohippocampectomy. Only $10 \%$ of TLE patients with HS, who are treated with AEDs, become seizure-free which emphasizes the

\footnotetext{
* Correspondence: Idesouza@fcm.unicamp.br

'Laboratory of Pediatric Endocrinology, Center for Investigation in Pediatrics, University of Campinas, PO Box 6111, Campinas, SP 13083-970, Brazil

Full list of author information is available at the end of the article
}

importance of HS as a prognostic factor [1]. HS is characterized by an abnormal increase in the number of astrocytes associated with the destruction of nearby neurons (astrogliosis) [2]. One of the primary events in seizure-induced cell death in the hippocampus is the excessive release of glutamate with consequent overload in intracellular calcium influx [3]. Within the neuronal cells, sophisticated homeostatic mechanisms control calcium levels. Altered $\mathrm{Ca}^{2+}$ sensitivity or defective $\mathrm{Ca}^{2+}$ regulation appear to be involved in the aging process, contributing to the progressive neurodegeneration in Alzheimer's disease and the intensified susceptibility to cell death after a seizure or stroke $[3,4]$.

\section{Biomed Central}

(c) 2013 Teocchi et al.; licensee BioMed Central Ltd. This is an Open Access article distributed under the terms of the Creative Commons Attribution License (http://creativecommons.org/licenses/by/2.0), which permits unrestricted use, distribution, and reproduction in any medium, provided the original work is properly cited. 
Klotho (KL), originally identified as an anti-aging protein, is involved in multiple functions in many systems and acts as an important calciophosphoregulatory hormone [5]. KL mRNA is expressed only in limited organs, that is the brain, kidney, reproductive organs, pituitary gland and parathyroid glands [6,7]. Its cerebral function is unclear, however Klotho knockout $\left(\mathrm{Kl}^{-/-}\right)$mice exhibit a phenotype resembling human aging, showing neural degeneration and a reduction of synapses in the hippocampus [6]. In addition, KL regulates the cellular lifespan of human cells by repressing the pro-apoptotic tumor protein p53 (TP53) [8], which regulates a number of apoptosis-related genes.

Important components and features of medial TLE, such as hippocampal intracellular calcium imbalance, neurodegeneration, hippocampal atrophy and cognitive decline, led us to question whether KL would also be downregulated in temporal lobe epilepsy associated with hippocampal sclerosis (TLE(HS)) patients. Furthermore, several studies assert that inflammation has a crucial role in epileptogenesis [9] and an increasing body of evidence connects astrogliosis to neuroinflammation [10]. In epilepsy, the pleiotropic cytokine TNF is indicated as being an important effector/mediator of neuroinflammation and cell death [9,11-15]. Interestingly, it has been demonstrated that TNF downregulates KL through the transcription nuclear factor kappa B (NFkB) in animal models of chronic kidney disease and colitis $[16,17]$. Since inflammation and neurodegeneration seem to be connected in HS, our objective was to verify if the triad KL-NFKB1-TNF is also dysregulated in TLE(HS).

\section{Methods}

Ethical approval was certified by the "Comitê de Ética da Faculdade de Ciências Médicas da Unicamp (CEP n 470/ 2003)".

\section{Patients, post mortem controls and tissues}

Electroencephalogram (EEG) video monitoring/telemetry was performed on all patients to confirm the onset of seizure in the medial temporal lobe. Dual pathologies or multifocal epilepsies were not identified. Hippocampal atrophy was detected by magnetic resonance imaging (MRI) in all patients.

Each patient signed an informed consent agreement to allow scientific use of the tissue. All procedures were carried out with the approval of the local research ethics committee, and in compliance with institutional guidelines and relevant laws.

Fourteen TLE(HS) patients had the amygdalohippocampectomy procedure performed for therapeutic reasons (Table 1). Hippocampal tissue samples from all 14 patients were immediately collected and divided into two parts. One portion was immediately snap-frozen in liquid nitrogen and stored at $-80^{\circ} \mathrm{C}$ until RNA isolation occurred. The second portion was fixed for histopathological analysis and HS was confirmed in all of them.

Five post mortem control hippocampal tissue samples (one female, four males; $28.2 \pm 13.1$ years; range from 19 to 50 years old) were provided by the Instituto Médico Legal (IML) de Campinas. Despite some traumatic deaths, no neurological abnormalities were detected. Subjects passed away unexpectedly and instantly, which minimizes

Table 1 Clinical and demographic features of TLE(HS) patients

\begin{tabular}{|c|c|c|c|c|c|c|c|}
\hline Patients & Gender & Age (years) & Side of HS & Duration (years) & Last seizure (days before surgery) & TLE form & AED during surgery \\
\hline TLE 01 & $\mathrm{~F}$ & 34.6 & L & 28.6 & nd & Familial & PHT \\
\hline TLE 02 & $\mathrm{~F}$ & 29.1 & L & 22.1 & 2 & Sporadic & CBZ \\
\hline TLE 03 & $\mathrm{~F}$ & 23.8 & $\mathrm{R}$ & 22.3 & 7 & Sporadic & CBZ \\
\hline TLE 04 & M & 42.8 & $\mathrm{R}$ & 41.2 & 3 & Sporadic & CBZ \\
\hline TLE 05 & M & 41.2 & L & 34.2 & 5 & Sporadic & CBZ \\
\hline TLE 06 & M & 50.8 & $\mathrm{R}$ & 48.8 & 7 & Sporadic & CBZ \\
\hline TLE 07 & M & 12.7 & L & 9.7 & 3 & Sporadic & CBZ, PHT \\
\hline TLE 08 & $\mathrm{~F}$ & 43.8 & $B(L)^{a}$ & 41.8 & nd & Sporadic & CBZ, LTG \\
\hline TLE 09 & $\mathrm{~F}$ & 58.2 & $\mathrm{R}$ & 57.7 & nd & Sporadic & OXC, VPA \\
\hline TLE 10 & $\mathrm{~F}$ & 54.9 & L & 50.9 & nd & Sporadic & CBZ \\
\hline TLE 11 & $\mathrm{~F}$ & 32.1 & $\mathrm{~L}$ & 31.6 & nd & Familial & CBZ \\
\hline TLE 12 & $\mathrm{~F}$ & 38.3 & L & 37.0 & 2 & Familial & OXC \\
\hline TLE 13 & $\mathrm{~F}$ & 54.1 & $\mathrm{~L}$ & 53.3 & nd & Sporadic & OXC, PHT \\
\hline TLE 14 & M & 34.4 & R & 34.2 & nd & Familial & OXC \\
\hline
\end{tabular}

aThe hippocampal side was more affected when bilateral. When the patient's last seizure was 'nd', the seizure most likely occurred over 7 days prior to surgery. TLE(HS), temporal lobe epilepsy associated with hippocampal sclerosis; M, male; F, female; B, bilateral; R, right; L, left; nd, not determined; AED, antiepileptic drug; CBZ, carbamazepine; PHT, phenytoin; OXC, oxcarbazepine; LTG, lamotrigine; VPA, valproate. 
the occurrence and progression of neuroinflammation. The post mortem delay averaged 7.8 hours (range from 6 to 9 hours).

\section{RNA extraction and reverse transcription quantitative PCR (RT-qPCR)}

To extract total RNA, $1 \mathrm{ml}$ of TRIzol Reagent (Life Technologies, Foster City, CA, USA) was added per 75 $\mathrm{mg}$ of frozen tissue samples, homogenized and then further processed according to the manufacturer's instructions. The RNA integrity number (RIN) mean in both the control and patient groups was similar: $6.68 \pm$ $0.9441(\mathrm{n}=5)$ and $6.155 \pm 0.2484(\mathrm{n}=11)$, respectively. Due to the fact that the RNA was unavailable, the RIN was not evaluated for three patient samples: TLE 03, TLE 11 and TLE 13. Subsequently, $1 \mu \mathrm{g}$ of total RNA of each sample was reverse transcribed into cDNA using 200 U of Superscript III Reverse Transcriptase (Life Technologies) and $3 \mu \mathrm{g}$ of Random Primers (Life Technologies) according to the manufacturer's instructions.

Sterilized and filtered DEPC-treated water was used in all cDNA synthesis reactions. Complementary DNA samples derived from the investigated genes were detected using an ABI PRISM 7500 Sequence Detection System (Life Technologies) and TaqMan Gene Expression Assays (Life Technologies): 5'-FAM-labeled probes and corresponding primer pairs (Table 2). Gene names are in accordance with the approved symbol from the HUGO Gene Nomenclature Committee (HGNC) database. To select the reference genes (endogenous controls), the study of Wierschke et al. on human epileptogenic tissues was considered [18]. Among 12 candidate genes, the algorithm NormFinder indicated hypoxanthine phosphoribosyltransferase 1 (HPRT1), enolase 2 (gamma, neuronal) (ENO2) and TATA box binding protein $(T B P)$ as good normalization factors, since as single genes their expression levels were among the five most stable. Glyceraldehyde-3-phosphate dehydrogenase $(G A P D H)$, a very often used reference gene, showed a relatively unstable expression. However, to reinforce our results, we opted to test all four reference genes. Glial fibrillary acidic protein (GFAP) was used as an upregulation control [18-20]. Each qPCR was run as triplicates with $10 \mathrm{ng}$ cDNA sample in $6.25 \mu \mathrm{l}$ TaqMan Gene Expression Master Mix (Life Technologies), 0.625 $\mu \mathrm{l}$ of the respective probe/primer mix, and $0.625 \mu \mathrm{l}$ purified and deionized $\mathrm{H}_{2} \mathrm{O}$.

The amplification of all samples was of the same efficiency for precise quantification of reverse transcription quantitative PCR (RT-qPCR) data. Serial fivefold dilutions, starting with $250 \mathrm{ng}$ of cDNA from the RNA quantification, of a cDNA solution pooled from the control group was used. The mean $C_{T}$ values, measured in triplicates, versus the $\log 10$ of the dilution was plotted. The values from linear regressions applied to these plots were also presented (not shown). The amplification efficiencies $\left(\mathrm{E}=10^{(-1 / \text { slope })}\right)$ were close to $1.0(100 \%)$.

\section{Data analysis}

Relative gene expression quantification data was generated and analyzed using the 7500 Software version 2.0.5 (Life Technologies). One of the post mortem control samples was randomly chosen as the benchmark and the quantification data from the other samples, including controls and patients, was evaluated according to this reference sample, which always had a relative quantification of 1.0. This allowed the two groups (post mortem controls and TLE(HS) patients) to be statistically compared.

The GraphPad Prism 5 software version 5.04 for Windows was used for the statistical analysis (San Diego, CA, USA; www.graphpad.com). The Mann-Whitney $U$ test was used for comparison between data from the control group $(n=5)$ versus the patient group $(n=14)$. All comparison data are presented as mean and SD. Correlation among the target genes was performed by the Spearman's rank correlation (Spearman's R). The

Table 2 Genes and gene expression assays analyzed in this study

\begin{tabular}{|c|c|c|c|c|c|c|c|}
\hline $\begin{array}{l}\text { Gene } \\
\text { symbol }\end{array}$ & Name & Task & $\begin{array}{l}\text { TaqMan Assay } \\
\text { number }\end{array}$ & $\begin{array}{l}\text { Amplicon } \\
\text { (bp) }\end{array}$ & Slope & $\mathrm{R}^{2}$ & Efficiency \\
\hline ENO2 & Enolase 2 (gamma, neuronal) & Reference gene & Hs00157360_m1 & 77 & -3.356 & 0.994 & 98.61 \\
\hline GAPDH & Glyceraldehyde-3-phosphate dehydrogenase & Reference gene & $4333764 \mathrm{~F}$ & 122 & -3.313 & 0.996 & 100.36 \\
\hline GFAP & Glial fibrillary acidic protein & $\begin{array}{l}\text { Upregulation } \\
\text { marker }\end{array}$ & Hs00909236_m1 & 59 & -3.414 & 0.999 & 96.29 \\
\hline HPRT1 & Hypoxanthine phosphoribosyltransferase 1 & Reference gene & $4333768 \mathrm{~F}$ & 100 & -3.306 & 0.988 & 100.67 \\
\hline KL & Klotho & Target & Hs00183100_m1 & 74 & -3.396 & 0.998 & 97.02 \\
\hline NFKB1 & $\begin{array}{c}\text { Nuclear factor of kappa light polypeptide gene } \\
\text { enhancer in B-cells } 1\end{array}$ & Target & Hs00765730_m1 & 66 & -3.388 & 0.997 & 97.30 \\
\hline TBP & TATA box binding protein & Reference gene & Hs99999910_m1 & 127 & -3.407 & 0.993 & 96.57 \\
\hline TNF & Tumor necrosis factor & Target & Hs99999043_m1 & 85 & -3.266 & 0.991 & 102.39 \\
\hline
\end{tabular}


reference sample was excluded from correlation tests and differences of $P<0.05$ were considered significant.

\section{Results and discussion}

The quality of the RNA and the reliability of reference genes to quantify gene expression in surgical tissue are crucial in interpreting epilepsy-related changes of gene expression $[18,21]$. The similarity in the RIN average between TLE patients and the control group (6.68 \pm 0.9441 and $6.155 \pm 0.2484$, respectively) reinforces our results. Post mortem delay has always been considered a major factor when interpreting the accuracy of results from human tissue studies; however, this may not be a factor for human brain RNA [21]. Durrenberger et al. concluded that post mortem delay caused only a minor deterioration and had no effect on RNA quality. The same results were found in previous research mentioned in their report [21]. We worked with a post mortem delay of between 6 to 9 hours, which would not seem to contradict the findings of the Durrenberger study.

Our results (Figure 1) showed a dramatic increase on $T N F$ relative mRNA expression in hippocampal tissue of TLE(HS) patients in comparison with the post mortem controls $(P<0.005$, regardless of the reference gene). Despite the same $P$ value for the results regarding the four reference genes used, the TNF expression mean in patients had an ample variation: from $29.61 \pm 8.55$ $(T B P)$ to $110.4 \pm 58.82$ (HPRT1). The combination of $E N O 2$ and TBP as the normalization factor proved to be very stable in epileptogenic tissues [18]. Therefore, in Figure 2, we used this combination to show the relative TNF expression individually by subject.

Our data suggests that the marked TNF upregulation in patients' tissues corroborates with the chronic hippocampal inflammation in TLE(HS). Table 1 shows that several patients had their last seizure several days before the surgery, suggesting that the high TNF expression levels were frequent, signaling that chronic hippocampal inflammation could be intrinsic to the refractory TLE(HS) syndrome. A number of studies in animal models indicate that seizures induce TNF expression in the brain [9,11-14]. Our findings confirm that a similar induction also occurs in TLE patients. However, despite the intense investigation of the TNF system and its effects in seizure models, there is not unanimous agreement on its effects in TLE(HS) and clinical studies are scarce [11]. Moreover, similar to recent findings on inflammatory disease models $[16,17]$, our data indicates that the synthesis of $\mathrm{KL}$ is reduced in the sclerotic hippocampus and TNF may downregulate KL through NFkB in TLE(HS) (Figures 1 and 2).

While $K L$ mRNA was significantly downregulated (HPRT1 and TBP: $P<0.001$; GAPDH: $P<0.02$; ENO2: $P$

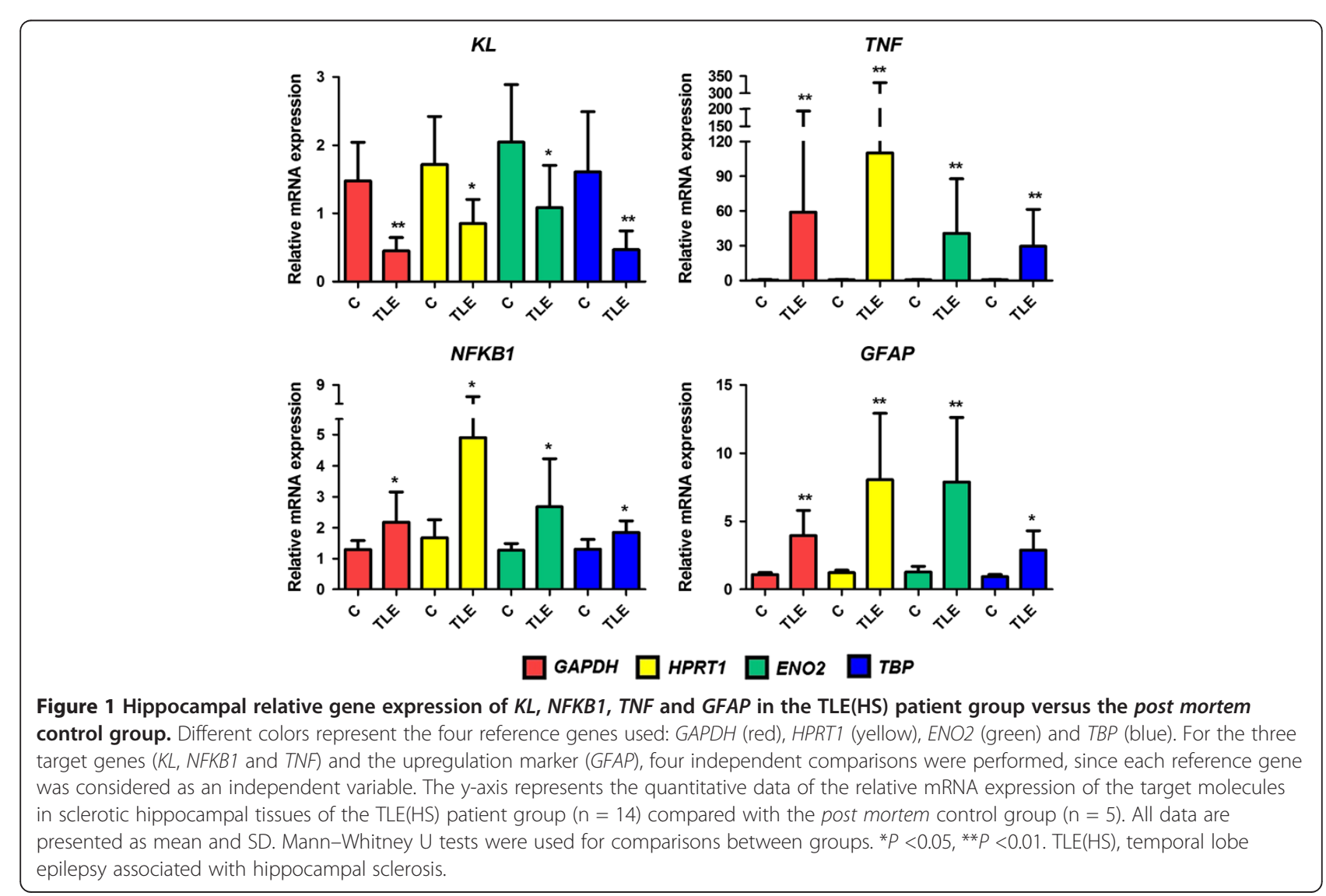



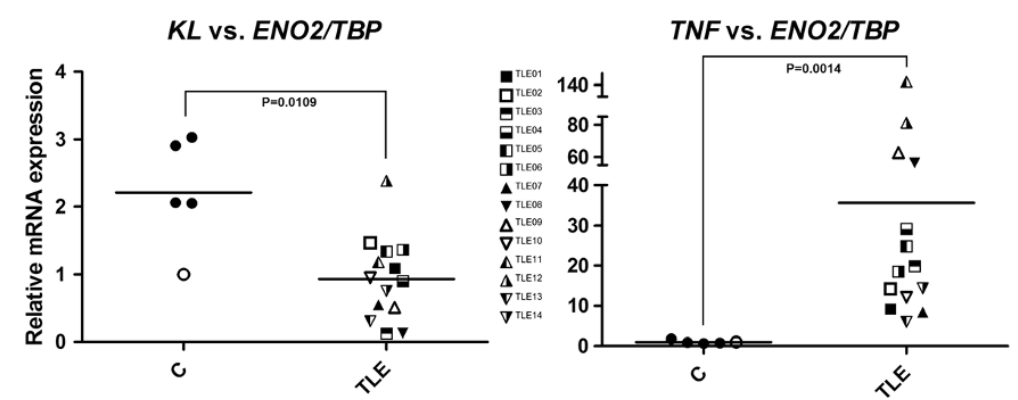

Figure 2 Dispersion of the relative gene expression of $K L$ and $T N F$ in the hippocampus of TLE(HS) patients and post mortem controls. The $y$-axis represents the quantitative data of the relative mRNA expression of $K L$ and TNF. The $x$-axis corresponds to the two groups: post mortem controls ( $n=5$, circles) and TLE(HS) patients ( $n=14$, squares and triangles). In the control group, the unfilled circle represents the calibrator sample, whose gene expression is always 1.0. The combination of ENO2 and TBP was used as the reference gene. Mann-Whitney $U$ tests were used for comparison between groups. TLE(HS), temporal lobe epilepsy associated with hippocampal sclerosis.

$<0.03)$, the expression level of $N F K B 1$ was also augmented in patients (GAPDH, HPRT1 and ENO2: $P$ $<0.02$; TBP: $P<0.03$ ) (Figure 1). It remains to be elucidated whether the KL depressed expression has a role in TLE(HS) physiopathology or is only a secondary change caused by the imbalance of calcium or phosphate and/or the progression of HS in the medial TLE syndrome. Since KL is a pleiotropic protein with different functions on many systems, our findings on $K L$ downregulation opens up a gamut of study possibilities in HS pathophysiology comprehension.

We initially highlighted two specific functions assigned to KL: it has a stimulating effect on the $\mathrm{Na}^{+} / \mathrm{K}^{+}$ATPase pump activity [22] and it influences the Wnt signal pathway [23]. Considering the importance of $\mathrm{Na}^{+} / \mathrm{K}^{+}$ATPase activity in neuronal electrical activity and excitability [24], it is important to determine if $\mathrm{KL}$ regulates $\mathrm{Na}^{+} / \mathrm{K}^{+}$ ATPase in the hippocampus, which could be involved with the evident synaptic reduction found in $\mathrm{Kl}^{-/-}$mice $[6,7]$. The molecular mechanisms regarding the neurodegenerative feature found in $\mathrm{Kl}^{-/-}$mice and analogously to HS have not yet been elucidated. By acting on the Wnt signaling, KL offers an interesting outlook as it suppresses several Wnt family members [23]. It has been demonstrated that stimulation of Wnt signaling contributes to stem and progenitor cell senescence, and persistent decreased KL expression may affect the rate of cellular aging and have harmful impact on tissue repair mechanisms [17]. This could be a key factor in HS progression.

There is another connection between KL depression and astrogliosis. By suppressing TP53 and negatively regulating cyclin-dependent kinase inhibitor 1 (CDKN1A, also known as p21) protein levels, KL not only inhibits apoptosis but also modulates the lifespan of human cells, which may be associated with increased signaling through the insulin/insulin-like growth factor 1 (IGF-1) pathway [8]. This growth factor has a significant role in non-neuronal modulation and multiple reports have indicated that astrocytes are the main target of IGF-1 by regulating their response to tissue injury [25]. Since KL may inhibit the insulin/IGF-1 pathway [26], its downregulation could support astrogliosis by a detrimental effect on neurons and astrocyte proliferation. In fact, $\mathrm{Kl}^{-/-}$mice have neuronal cell degeneration with a drastic increase in GFAP levels [27]. As expected, GFAP was upregulated in patients (GAPDH, HPRT1 and ENO2: $P<0.001$; TBP: $P<0.02$ ), which supports astrogliosis (Figure 1).

Furthermore, KL has been considered an antiinflammatory protein and this property could be one of its most striking features. In the endothelium, KL confers protection against nitric oxide (NO)-induced dysfunction [28], reduces the expression of adhesion molecules [28] and potentially regulates $\mathrm{T}$ cell functions [29]. In 2007, Witkowski et al. reported that KL was downregulated in $\mathrm{CD}_{4}^{+}$lymphocytes at the mRNA, protein and enzymatic (beta-glucoronidase) activity levels in healthy, older adults and especially in rheumatoid arthritis (RA) patients [29]. Regardless of the unclear link between KL activity and $\mathrm{CD} 4^{+}$cell function, they proposed that KL might be involved in physiological antiinflammatory responses in young individuals, but these responses decreased in both healthy older adults and RA patients. Their hypothesis was supported by the fact that $\mathrm{KL}$ expression and activity reduction, in both older adults and RA patients' lymphocytes, occurred in concert with the downregulation of CD28, a TNF-increased dependent $\mathrm{T}$ cell costimulatory molecule.

The $\mathrm{Kl}^{-/-}$mouse also exhibits atherosclerosis and endothelial dysfunction, which led Maekawa et al. [28] to test the effect of $\mathrm{KL}$ on vascular inflammation. KL suppressed the TNF-induced expression of adhesion molecules and NFkB activation in endothelial cells in vitro (human umbilical vein endothelial cells (HUVECs)) and ex vivo (organ culture of the rat aorta). 
Moreover, KL reversed the repression of the nitric oxide synthase 3 (NOS3) phosphorylation by TNF and inhibited the TNF-induced monocyte adhesion to HUVECs. These results suggest that KL may have a function in the modulation of endothelial inflammation, especially by TNF-induced NFkB inhibition. Therefore, it is plausible that KL downregulation could further exacerbate the TLE(HS) associated chronic inflammatory condition.

Moreno et al. related that the inflammatory cytokines tumor necrosis factor ligand superfamily member 12 (TNFSF12, also known as TWEAK) and TNF downregulate $\mathrm{KL}$ in renal tubular cells through an NFkB-dependent mechanism mediated by histone deacetilase 1 (HDAC1) [16]. In this regard, they observed that the HDAC inhibitors trichostatin A (TSA) or valproic acid prevented repression of $\mathrm{KL}$ induced by TWEAK or TNF. Among the patients studied, only TLE 09 was taking valproate during the surgery and only TLE 06 took this medication in the past. We did not observe any particular difference in these patients compared with the others. $K L$ expression was negatively correlated with NFBK1 or TNF expression, while the pair TNF and NFKB1 showed a positive correlation. This suggests that NFkB in patients is most likely modulated by TNF or even KL [28] and not by AEDs, although further studies are required to test the influence of AEDs in the gene expression of our targets. Gene expression data correlation was found in the three pairs tested: $K L$ NFKB1 (Spearman's $\mathrm{R}=-0.3140 ; P=0.0091$ ), $K L-T N F$ (Spearman's $\mathrm{R}=-0.3283 ; P=0.0063$ ), and NFKB1-TNF (Spearman's $\mathrm{R}=0.4441 ; P=0.0001$ ).

In addition, Thurston et al. showed that in mouse models of inflammatory bowel disease the degree of $\mathrm{KL}$ inhibition was related to the severity of colitis and that attenuation of inflammation with a neutralizing antiTNF antibody impeded this inhibition [17]. Furthermore, the neurodegenerative feature found in $\mathrm{Kl}^{-/-}$mice suggests that KL in the hippocampus may act as a protective autocrine hormone and its absence causes neuronal loss [30].

Our work on the mRNA level suggests that the triad $K L-N F K B 1-T N F$ is disrupted in the hippocampus from medically intractable TLE patients. Based on the KL function studies discussed here, we propose the first mechanistic insights into the role that this triad may play in the pathogenesis of medial TLE. It is conceivable that there is a major involvement of the KL-TNF axis in the pathogenesis of TLE(HS), particularly under chronic inflammatory conditions. Further research on the protein level will strengthen our results and the design of functional studies will be able to elucidate the role of our targets, especially $\mathrm{KL}$, in the normal and pathological hippocampus. Due to the KL hormonal property
$[7,31]$ and TNF tissue diffusion as a cytokine [32,33], we believe that the epilepsy-associated inflammation is a widespread event in the hippocampus. Finally, since KL is detectable in cerebrospinal fluid $[7,31,34]$, it is a potential candidate as an inflammatory biomarker in epilepsy. The inflammatory component of epilepsy is not a secondary phenomenon or complication of the pathology. It is more likely involved in the mechanisms that sustain neuronal hyperexcitability, the onset and recurrence of seizures, and progression and severity of the disease [15]. The determination of a reliable biomarker of brain inflammation is urgent, in view of the fact that a number of patients would benefit from an antiinflammatory therapy.

\section{Abbreviations}

AED: antiepileptic drug; CBZ: carbamazepine; CDKN1A: cyclin-dependent kinase inhibitor 1 (p21 Cip1); DEPC: diethylpyrocarbonate;

EEG: electroencephalogram; ENO2: enolase 2 (gamma neuronal); GAPDH: glyceraldehyde 3-phosphate dehydrogenase; GFAP: glial fibrillary acidic protein; HDAC1: histone deacetilase 1; HGNC: HUGO Gene Nomenclature Committee; HPRT1: hypoxanthine phosphoribosyltransferase 1; HS: hippocampal sclerosis; HUVEC: human umbilical vein endothelial cell; IGF-1: insulin-like growth factor 1 (somatomedin C); IML: Instituto Médico Legal; KL: Klotho; $\mathrm{Kl}^{-1-}$ : Klotho knockout; LTG: lamotrigine; MRI: magnetic resonance imaging; NFkB: nuclear factor kappa B; NFKB1: nuclear factor of kappa light polypeptide gene enhancer in B-cells 1; NOS3: nitric oxide synthase 3 (endothelial cell); OXC: oxcarbazepine; PCR: polymerase chain reaction; PHT: phenytoin; RA: rheumatoid arthritis; RIN: RNA integrity number; RT-qPCR: reverse transcription quantitative PCR; TBP: TATA box binding protein; TLE: temporal lobe epilepsy; TLE(HS): temporal lobe epilepsy associated with hippocampal sclerosis; TNF: tumor necrosis factor; TNFSF12: tumor necrosis factor ligand superfamily member 12 (TWEAK); TP53: tumor protein p53; TSA: trichostatin A; VPA: valproate.

\section{Competing interest}

All authors declare that they have no competing interest.

\section{Authors' contributions}

MAT designed the study, collected clinical data, performed the experiments, analyzed the data, prepared the figures and tables, and drafted the manuscript. AEDF collected clinical data and helped to perform the experiments. EPLO and HT are neurosurgeons and operated on patients. $L D-L$ designed and coordinated the study and helped to draft the manuscript. All authors read and approved the final manuscript.

\section{Acknowledgements}

This study was financially supported by the São Paulo Research Foundation (FAPESP; processo 05/565778-4) and the Coordenação de Aperfeiçoamento de Pessoal de Nível Superior (CAPES). Quantitative PCRs were carried out in the Multiuser Laboratory (www.laboratoriomultiusuario.com.br) and RIN detection was performed in the Central Laboratory of High Performance Technologies (LaCTAD; www.lactad.unicamp.br), both also supported by FAPESP. MAT wishes to thank David Elieff for helping with the English language review.

\section{Author details}

${ }^{1}$ Laboratory of Pediatric Endocrinology, Center for Investigation in Pediatrics, University of Campinas, PO Box 6111, Campinas, SP 13083-970, Brazil. ${ }^{2}$ Department of Neurology, Faculty of Medical Sciences, University of Campinas, PO Box 6111, Campinas, SP 13083-970, Brazil.

Received: 1 November 2012 Accepted: 19 March 2013 Published: 1 May 2013 


\section{References}

1. Semah F, Picot MC, Adam C, Broglin D, Arzimanoglou A, Bazin B, Cavalcanti $D$, Baulac M: Is the underlying cause of epilepsy a major prognostic factor for recurrence? Neurology 1998, 51:1256-1262.

2. Greenfield JG, Graham DI, Lantos PL: Greenfield's Neuropathology. 6th edition. London: Arnold; 1997.

3. Delorenzo RJ, Sun DA, Deshpande LS: Cellular mechanisms underlying acquired epilepsy: the calcium hypothesis of the induction and maintainance of epilepsy. Pharmacol Ther 2005, 105:229-266.

4. Raza M, Deshpande LS, Blair RE, Carter DS, Sombati S, DeLorenzo RJ: Aging is associated with elevated intracellular calcium levels and altered calcium homeostatic mechanisms in hippocampal neurons. Neurosci Lett 2007, 418:77-81

5. Huang CL, Moe OW: Klotho: a novel regulator of calcium and phosphorus homeostasis. Pflugers Arch 2011, 462:185-193.

6. Kuro-o M, Matsumura Y, Aizawa H, Kawaguchi H, Suga T, Utsugi T, Ohyama Y, Kurabayashi M, Kaname T, Kume E, Iwasaki H, lida A, Shiraki-lida T, Nishikawa S, Nagai R, Nabeshima Yl: Mutation of the mouse klotho gene leads to a syndrome resembling ageing. Nature 1997, 390:45-51.

7. Li SA, Watanabe M, Yamada H, Nagai A, Kinuta M, Takei K: Immunohistochemical localization of Klotho protein in brain, kidney, and reproductive organs of mice. Cell Struct Funct 2004, 29:91-99.

8. de Oliveira RM: Klotho RNAi induces premature senescence of human cells via a p53/p21 dependent pathway. FEBS Lett 2006, 580:5753-5758.

9. Ravizza T, Balosso S, Vezzani A: Inflammation and prevention of epileptogenesis. Neurosci Lett 2011, 497:223-230.

10. Foresti ML, Arisi GM, Shapiro LA: Role of glia in epilepsy-associated neuropathology, neuroinflammation and neurogenesis. Brain Res Rev 2011, 66:115-122.

11. Li G, Bauer S, Nowak M, Norwood B, Tackenberg B, Rosenow F, Knake S, Oertel WH, Hamer HM: Cytokines and epilepsy. Seizure 2011, 20:249-256.

12. Plata-Salaman $C R$, llyin SE, Turrin NP, Gayle D, Flynn MC, Romanovitch $A E$, Kelly ME, Bureau Y, Anisman H, Mclntyre DC: Kindling modulates the IL1beta system, TNF-alpha, TGF-beta1, and neuropeptide mRNAs in specific brain regions. Brain Res Mol Brain Res 2000, 75:248-258.

13. Godlevsky LS, Shandra AA, Oleinik AA, Vastyanov RS, Kostyushov W, Timchishin OL: TNF-alpha in cerebral cortex and cerebellum is affected by amygdalar kindling but not by stimulation of cerebellum. Pol $\mathrm{J}$ Pharmacol 2002, 54:655-660.

14. Vezzani A, Moneta D, Richichi C, Aliprandi M, Burrows SJ, Ravizza T, Perego $C$, De Simoni MG: Functional role of inflammatory cytokines and antiinflammatory molecules in seizures and epileptogenesis. Epilepsia 2002, 43(Suppl 5):30-35.

15. Vezzani A, Friedman A: Brain inflammation as a biomarker in epilepsy. Biomark Med 2011, 5:607-614.

16. Moreno JA, Izquierdo MC, Sanchez-Nino MD, Suarez-Alvarez B, Lopez-Larrea C, Jakubowski A, Blanco J, Ramirez R, Selgas R, Ruiz-Ortega M, Egido J, Ortiz A, Sanz AB: The inflammatory cytokines TWEAK and TNF-alpha reduce renal Klotho expression through NF-kappaB. J Am Soc of Nephrol 2011 22:1315-1325

17. Thurston RD, Larmonier CB, Majewski PM, Ramalingam R, Midura-Kiela M, Laubitz D, Vandewalle A, Besselsen DG, Muhlbauer M, Jobin C, Kiela PR, Ghishan FK: Tumor necrosis factor and interferon-gamma down-regulate Klotho in mice with colitis. Gastroenterology 2010, 138:1384-1394.

18. Wierschke S, Gigout S, Horn P, Lehmann TN, Dehnicke C, Brauer AU, Deisz RA: Evaluating reference genes to normalize gene expression in human epileptogenic brain tissues. Biochem Biophys Res Commun 2010, 403:385-390.

19. Becker AJ, Chen J, Paus S, Normann S, Beck H, Elger CE, Wiestler OD, Blumcke I: Transcriptional profiling in human epilepsy: expression array and single cell real-time qRT-PCR analysis reveal distinct cellular gene regulation. Neuroreport 2002, 13:1327-1333.

20. Ozbas-Gerceker F, Redeker S, Boer K, Ozguc M, Saygi S, Dalkara T, Soylemezoglu F, Akalan N, Baayen JC, Gorter JA, Aronica E: Serial analysis of gene expression in the hippocampus of patients with mesial temporal lobe epilepsy. Neuroscience 2006, 138:457-474.

21. Durrenberger PF, Fernando S, Kashefi SN, Ferrer I, Hauw JJ, Seilhean D, Smith C, Walker R, Al-Sarraj S, Troakes C, Palkovits M, Kasztner M, Huitinga I, Arzberger T, Dexter DT, Kretzschmar H, Reynolds R: Effects of antemortem and postmortem variables on human brain mRNA quality: a BrainNet Europe study. J Neuropathol Exp Neurol 2010, 69:70-81.
22. Sopjani M, Alesutan I, Dermaku-Sopjani M, Gu S, Zelenak C, Munoz C, Velic A, Foller M, Rosenblatt KP, Kuro-o M, Lang F: Regulation of the $\mathrm{Na}+/ \mathrm{K}+$ ATPase by Klotho. FEBS Lett 2011, 585:1759-1764.

23. Liu H, Fergusson MM, Castilho RM, Liu J, Cao L, Chen J, Malide D, Rovira II, Schimel D, Kuo CJ, Gutkind JS, Hwang PM, Finkel T: Augmented Wnt signaling in a mammalian model of accelerated aging. Science 2007 317:803-806.

24. Brines ML, Tabuteau H, Sundaresan S, Kim J, Spencer DD, de Lanerolle N: Regional distributions of hippocampal $\mathrm{Na}+, \mathrm{K}(+)$-ATPase, cytochrome oxidase, and total protein in temporal lobe epilepsy. Epilepsia 1995, 36:371-383.

25. Fernandez S, Fernandez AM, Lopez-Lopez C, Torres-Aleman I: Emerging roles of insulin-like growth factor-I in the adult brain. Growth Horm IGF Res 2007, 17:89-95.

26. Wang Y, Sun Z: Current understanding of klotho. Ageing Res Rev 2009, 8:43-51

27. Shiozaki M, Yoshimura K, Shibata M, Koike M, Matsuura N, Uchiyama Y, Gotow T: Morphological and biochemical signs of age-related neurodegenerative changes in klotho mutant mice. Neuroscience 2008 152:924-941.

28. Maekawa Y, Ishikawa K, Yasuda O, Oguro R, Hanasaki H, Kida I, Takemura Y, Ohishi M, Katsuya T, Rakugi H: Klotho suppresses TNF-alpha-induced expression of adhesion molecules in the endothelium and attenuates NF-kappaB activation. Endocrine 2009, 35:341-346.

29. Witkowski JM, Soroczynska-Cybula M, Bryl E, Smolenska Z, Jozwik A: Klothoa common link in physiological and rheumatoid arthritis-related aging of human CD4+ lymphocytes. J Immunol 2007, 178:771-777.

30. Abraham CR, Chen C, Cuny GD, Glicksman MA, Zeldich E: Small-molecule Klotho enhancers as novel treatment of neurodegeneration. Future Med Chem 2012, 4:1671-1679.

31. German DC, Khobahy I, Pastor J, Kuro OM, Liu X: Nuclear localization of Klotho in brain: an anti-aging protein. Neurobiol Aging 2012, 33:1483.

32. Falsig J, Porzgen P, Lotharius J, Leist M: Specific modulation of astrocyte inflammation by inhibition of mixed lineage kinases with CEP-1347. J Immunol 2004, 173:2762-2770.

33. Nadeau S, Rivest S: Role of microglial-derived tumor necrosis factor in mediating CD14 transcription and nuclear factor kappa B activity in the brain during endotoxemia. J Neurosci 2000, 20:3456-3468.

34. Sathyanesan M, Girgenti MJ, Banasr M, Stone K, Bruce C, Guilchicek E, Wilczak-Havill K, Nairn A, Williams K, Sass S, Duman JG, Newton SS: A molecular characterization of the choroid plexus and stress-induced gene regulation. Trans/ Psychiatry 2012, 2:e139.

doi:10.1186/1742-2094-10-53

Cite this article as: Teocchi et al:: Hippocampal gene expression dysregulation of Klotho, nuclear factor kappa B and tumor necrosis factor in temporal lobe epilepsy patients. Journal of Neuroinflammation 2013 10:53.

\section{Submit your next manuscript to BioMed Central and take full advantage of:}

- Convenient online submission

- Thorough peer review

- No space constraints or color figure charges

- Immediate publication on acceptance

- Inclusion in PubMed, CAS, Scopus and Google Scholar

- Research which is freely available for redistribution 